\title{
Cognitive-behavior therapy for compulsive checking in OCD
}

Article

Accepted Version

Radomsky, A. S., Shafran, R., Coughtrey, A. E. and Rachman, S. (2010) Cognitive-behavior therapy for compulsive checking in OCD. Cognitive and Behavioral Practice, 17 (2). pp. 119131. ISSN 1077-7229 doi:

https://doi.org/10.1016/j.cbpra.2009.10.002 Available at https://centaur.reading.ac.uk/6918/

It is advisable to refer to the publisher's version if you intend to cite from the work. See Guidance on citing.

Published version at: http://dx.doi.org/10.1016/j.cbpra.2009.10.002

To link to this article DOI: http://dx.doi.org/10.1016/j.cbpra.2009.10.002

Publisher: Elsevier Ltd

All outputs in CentAUR are protected by Intellectual Property Rights law, including copyright law. Copyright and IPR is retained by the creators or other copyright holders. Terms and conditions for use of this material are defined in the End User Agreement.

\section{www.reading.ac.uk/centaur}

\section{CentAUR}

Central Archive at the University of Reading 
Reading's research outputs online 
Running Head: COMPULSIVE CHECKING

Cognitive-behavior therapy for compulsive checking in OCD

Adam S. Radomsky ${ }^{1}$, Roz Shafran ${ }^{2}$, S. Rachman ${ }^{3}$ and A. E. Coughtrey ${ }^{2}$

${ }^{1}$ Department of Psychology, Concordia University

${ }^{2}$ School of Psychology and Clinical Language Sciences, University of Reading

${ }^{3}$ Department of Psychology, University of British Columbia

Correspondence concerning this article should be addressed to Adam S. Radomsky, Department of Psychology, Concordia University, 7141 Sherbrooke St. West, SP-244, Montreal, QC, H4B 1R6, CANADA.

E-mail: adam.radomsky@concordia.ca 


\begin{abstract}
There is substantial evidence for the effectiveness of psychological treatments for OCD, and various approaches have been widely recommended. These approaches tend to be characterized by exposure and response prevention (ERP) and also tend to be applied equally to all forms of OCD. Patients/clients (and some therapists) often find ERP to be a difficult treatment, and both drop out and refusal rates are unacceptably high. Based on specific cognitive conceptualizations of different manifestations of OCD, new and refined cognitive treatment methods are now available. The present article describes a specific cognitively-based approach to the treatment of compulsive checking.
\end{abstract}

Keywords: OCD; compulsive checking; cognitive therapy; CBT; behavioural experiment. 
Cognitive-behaviour therapy for compulsive checking in OCD

There is substantial evidence for the effectiveness of psychological treatments for OCD, and a range of exposure-based methods have been recommended by medical advisory bodies such as the National Institutes for Clinical Excellence in the UK and the National Institute of Mental Health in the U.S. However, there is a need for new and refined methods (Wilhelm, 2001), and in keeping with the move towards developing increasingly specific treatments (e.g., on the treatment of obsessions, Rachman, 2003), the present article describes a specific approach to the treatment of compulsive checking.

\section{The nature of compulsive checking}

Compulsive checking is a common form of OCD, perhaps the most common (Rachman \& Hodgson, 1980). In a study by Foa and colleagues (2005), checking was the most prevalent compulsion and was reported by $28.8 \%$ of patients, followed closely by compulsive washing and/or cleaning, reported by $26.5 \%$ of patients. We all engage in safety checking behavior (e.g., how often do you check to make sure you have your tickets and/or passport on the way to the airport?), but compulsive checking is extreme, pre-occupying, maladaptive, distressing, and can be incapacitating. It is associated with excessive anxiety and tension, feelings of guilt, avoidance behavior, elevated vigilance, repeated requests for reassurance, biases of memory and of attention, other cognitive biases (e.g., thought-action fusion), inflated responsibility, perfectionism, and a resistance to change. The most common theme is an attempt to prevent harm coming to other people and/or oneself. Typical examples of compulsive checking include compulsively checking that family members are safe, repeatedly re-tracing the route that one has 
driven in order to confirm that one has not killed or injured a pedestrian, repeatedly checking that the doors and windows are securely closed. Checking can require hours to complete, and patients usually engage in compulsive checking on a daily basis.

\section{Checking and responsibility}

During the past fifteen years, advances have been made in explaining the nature of compulsive checking and emerging evidence from experimental investigations supports key aspects of the fresh thinking (e.g., Arntz, Voncken, \& Goosen, 2007; Radomsky, Gilchrist, \& Dussault, 2006; Haring, 2005; van den Hout \& Kindt, 2003a,b). The important role of inflated responsibility posited by Salkovskis (1985) has received wide support from the work of Ladouceur, Rheaume, and Aublet (1997); Arntz and colleagues (2007); van den Hout and Kindt (2004); Lopatka and Rachman (1995); Shafran (1997); Haring (2005); Radomsky, Rachman, and Hammond (2001), to name just a few. Broadly, deliberate increases in responsibility are followed by substantial increases in compulsive checking. These results have been found in patients with OCD (e.g., Arntz et al., 2007; Lopatka \& Rachman, 1995; Shafran, 1997) and in analogue studies on non-clinical participants (e.g., van den Hout \& Kindt, 2004; Ladouceur et al., 1995; Haring, 2005). In the absence of significant levels of responsibility, minimal or no checking takes place (Haring, 2005).

It has been suggested that there are several possible paths to inflated responsibility (Salkovskis, 1985; Salkovskis, Shafran, Rachman, \& Freeston, 1999; Coles \& Schofield, 2008). An early allocation of excessive responsibility in dysfunctional families and/or families in which a parent is chronically ill or dysfunctional can establish a lasting inflation of responsibility. At the other extreme, people who are overprotected during childhood and shielded from responsibility may find that leaving home is difficult to manage and respond to the early absence 
of responsibility by over-compensating. "Strict behavioural codes inculcated by respected authoritarian or authoritative sources" can promote excessive feelings of responsibility (Salkovskis et al., 1999, p.1061). A serious misfortune for which the person feels responsibility can produce a lasting and broad elevation of responsibility, as can a serious misfortune which the person believes was caused by their thoughts (i.e., thought-action fusion).

Inflated feelings of responsibility can be a considerable burden, and hence many people strenuously evade them. In the civil service (to pick a domain at random), evasion of responsibility can be an art form.

Cognitive model of compulsive checking (Rachman, 2002)

The theorizing by Salkovskis (1985) and accumulating experimental evidence on the nature of compulsive checking provided a basis for the specific explanation of compulsive checking. The cognitive theory of compulsive checking (Rachman, 2002) attempts to explain why and when checking behavior becomes compulsive, and also addresses the question of why the compulsive checking persists. A composite diagram outlining the model can be found in Figure 1.

Causal. It is proposed that three major components contribute to compulsive checking and they do so in a multiplicative manner. The three multipliers are inflated estimates/perceptions of the probability of a misfortune, inflated estimates/perceptions of the seriousness of the predicted misfortune, and an inflated sense of personal responsibility (Rachman, 2002). High levels of inflated responsibility supercharge the estimates/perceptions of the probability of a misfortune and the seriousness of the feared misfortune. These cognitive multipliers are proposed to lead to the onset of checking behavior (and also serve to maintain the behavior). 
Persistence. The persistence of compulsive checking is proposed to be attributable to a self-perpetuating cycle, in which checking paradoxically increases feelings of responsibility, corrodes confidence in one's memory, and impairs attention. It is hypothesized that checking causes more checking, in part because repeated checking produces memorial distrust and impaired attention. The problem is a loss of confidence generated by seemingly senseless repetitions. Repeatedly checking one's actions should enhance a person's confidence but it fails to do so (Coles, Radomsky \& Horng, 2006; Radomsky, Gilchrist \& Dussault, 2006; van den Hout \& Kindt, 2003a,b).

In addition to declining confidence in one's memory and an increase in responsibility, repeated checking is produces a lack of focus ("my head begins to feel fuzzy"), a decline in the ability to control one's thoughts, increasing difficulty in concentrating, and indecisiveness (van den Hout, Engelhard, de Boer, du Bois, \& Dek, 2008; van den Hout et al., 2009). One patient described it as an intermittent fault -“My brain switches off”. These consequences contribute to the self-perpetuating cycle that sustains the compulsive checking. The specific treatment for compulsive checking weakens this cycle by addressing each of these contributors to persistence.

\section{Research data}

It has been shown that among OCD patients with a primary problem of compulsive checking, a deliberate increase/decrease in their perceived degree of responsibility for carrying out selected sensitive actions in their own homes (e.g., using the stove) was directly related to checking behavior (Lopatka \& Rachman, 1995). Checking urges increased or decreased with changes in perceived responsibility. These results were subsequently confirmed at the Institute of Psychiatry in the U.K. (Shafran, 1997), and are consistent with laboratory research reported by 
Ladouceur, Leger, Rheaume, \& Dube (1996), Haring (2005), van den Hout and Kindt (2004), Radomsky et al. (2001) and Arntz et al. (2007).

Another line of research deals with the nature and causes of the memory problems encountered in compulsive checking. The hypothesis that repetitive checking produces a loss of confidence in one's memory (Coles, Radomsky, \& Horng, 2006; Radomsky et al., 2006) has provided independent support from a number of laboratories to work initially conducted at the University of Utrecht (van den Hout \& Kindt, 2003a). Recently it has been demonstrated that overt checking, and perseverative and compulsive-like staring causes uncertainty about the validity of one's perceptions (van den Hout et al., 2008; van den Hout et al., 2009).

In addition, we have tested the hypothesis that compulsive checking is generated by three multiplicative factors: probability estimates, predictions of seriousness of anticipated misfortunes, inflated personal responsibility. Using a scenario methodology 29 participants rated the strength of their urges to check in specified situations which involved some uncertainty. The three multiplicative factors were systematically varied along the dimensions of personal responsibility, probability of occurrence, seriousness of feared consequence. The predicted increases in urges to check were confirmed. The secondary prediction, that with only minimal personal responsibility, few or no checking urges would be reported was also confirmed (Haring, 2005). Recent findings from the University of Maastricht (Arntz et al., 2007) are consistent with the results of this research.

\section{Treatment}

The fundamental rationale for the treatment, helping patients to modify their key misinterpretations and the behavior that sustains the compulsions, is common to all forms of CBT (Clark \& Fairburn, 1997). The techniques of analysis and modification of misappraisals are 
similar, as are the methods of assessment. Many of the tactics are common to other forms of CBT, but the distinctive features of the specific treatment for compulsive checking in OCD are the emphasis on modifying the patient's feelings of responsibility and interrupting the selfperpetuating cycle and reducing the three multipliers. The method is used flexibly in order to meet the particular needs of each patient, and hence, in addition to the essential components set out above, adjunctive procedures are used as necessary. For example, clients/patients whose problems are increased by their tendency to engage in biased reasoning such as thought-action fusion (Shafran, Thordarson, \& Rachman, 1996), require particular help in overcoming this tendency. Behavioral experiments are an important technique and are used in tackling many of the patient's problems. The experiments are especially valuable because they generate immediate, personally credible information about the probabilities of misfortunes, the seriousness of the feared misfortune, and inflated responsibility. An outline of the content of treatment is provided in Table 1.

Table 1 - Treatment Content

Progress of treatment (Order is suggested, but not required)

1. Introductory didactic sessions including psychoeducation about OCD and compulsive checking

2. Cognitive analysis of responsibility and other relevant belief domains

3. Exercises in normalizing inflated responsibility

4. Exercises in transferring responsibility

5. Modification of probability estimates

6. Modification of catastrophizing expectations 
7. Modification of cognitive biases (including thought-action fusion)

8. Response prevention

9. Normalizing safety behavior, and discouragement of unadaptive safety behavior

10. Discouragement/Reduction of reassurance-seeking behavior

11. Restoring confidence in memory

12. Restoring confidence in concentration

13. Restoring confidence in ability to control one's thoughts

14. Reducing self-doubt

15. Reducing inappropriate guilt

16. Reducing hyper-vigilance

We suggest that prior to starting the treatment the therapist conducts a semi-structured interview for compulsive checking (see Appendix A for an example). In addition, therapists may wish to consider asking the patient/client to complete the Personal Significance Scale for compulsive checking (PSS-CHK; see Appendix B) as it assesses possible appraisals pertinent to compulsive checking behavior. (Alternate more established measures might include the OBQ44, OCCWG, 2005). We also recommend using self report measures of depression (e.g., the Beck Depression Inventory-II; Beck, Steer, \& Garbin, 1996) and of OCD symptoms, such as the Padua Inventory (Burns, Keortge, Formea \& Sternberger, 1996) or the Vancouver Obsessional Compulsive Inventory (VOCI; Thordarson et al., 2004).

Treatment begins with two introductory sessions in which the person's difficulties are assessed and formulated. VIDEO 1 illustrates this process. In the first two sessions, the nature of OCD is explained and the features and incidence of compulsive checking are described. The 
theory of compulsive checking is collaboratively developed and explained, with clinical examples (e.g., the effects of a transfer of responsibility, why most patients who fear driving over bridges or difficult roads usually feel more comfortable if someone else drives, why it is easier to leave one's home in the morning if someone else will be leaving after one has departed, more likely to re-trace one's journey if driving alone, minimal urges to re-trace a journey in which one was a passenger, why doubts arise about one's memory, etc). The nature of the treatment program, sessions and assessments are described. Patients are provided with in-session written material that covers these two sessions.

(Please view Video 1 here.)

The following sessions focus on the patient's specific compulsive checking behavior, its development and personal significance. These sessions are guided by the information collected in the pre-treatment assessment sessions (e.g., the type, degree and extensity of excessive feelings of responsibility).

\section{Behavioral experiments}

Behavioral experiments are extremely useful in collecting new and credible information about responsibility, probability and seriousness, as well as other checking-related appraisals or beliefs. They can be tailored to collect information about one of these dimensions or all of them. For example, the effects of completing a round of compulsive checking on perceived responsibility, and on the probability and seriousness of the feared event can be assessed in one such experiment. They are also useful for measuring the effects of repeated checking on the level of perceived responsibility (usually elevated).

The format for the behavioral experiments is to begin by establishing the patient's baseline estimates of the probability/seriousness/responsibility of the feared event or misfortune 
(or whatever the cognitive target of the experiment will be), and then to collect such estimates after the patient has completed say 10 checks, and again after 20 or 30, as appropriate. In this way the patient gathers information about the efficacy (minimal) of the checking - it seldom reduces their estimates of probability or seriousness, and can increase their sense of responsibility. For example:

Baseline estimates:

I believe there is an $80 \%$ chance of (the feared event) occurring I believe that the effects of (the event) would be $100 \%$ serious If (the event) occurs I will be $100 \%$ responsible After completing 10 checks, the patient makes new estimates. After completing 20 to 30 checks the patient makes new estimates. The information collected in the behavioral experiments generally demonstrates to the patient that repeated checking is NOT efficacious. Furthermore it is likely to be contributing to self-doubt (see below).

Estimating the probability of an adverse event.

Extreme estimates of the probability that catastrophic events will occur is a major element in compulsive checking and needs to be modified. A rough estimate of the number of occasions on which the patient anticipated with confidence that one of these misfortunes would occur is compiled (a blackboard helps here), and then balanced against the number of misfortunes that actually occurred. These estimates are used to emphasize that the patient's difficulties arise from a problem of thinking, not a problem of behavior. Approximate base rates of the feared accidents/misfortunes are supplied when possible. 
To begin, it is instructive to consider examples drawn from the patient's own experiences. Rough calculations are made of the number of times the patient has carried out the relevant task, and then the number of significant errors that they have made. An experienced pharmacist sought assistance because he was demoralized by a growing need to compulsively check his work, and was persistently tired because he went in to work an hour earlier than necessary and stayed on after working hours. He worked in a busy pharmacy and prepared approximately 50 prescriptions each day, a thousand a month. We jointly calculated that during the past ten years he had prepared 120,000 prescriptions. During this period he had made two 'significant errors', neither of which was actually of much consequence. A visual display of the calculations and results was impressive. In addition, we calculated the number of worrying thoughts about possible errors and the anticipated catastrophes, and placed them alongside the actual number of errors.

Probability estimates are constructed in this manner for each manifestation of compulsive checking, as appropriate. Analyses of the patient's exceedingly skewed estimates of probable harm are revealing and instructive, but do not automatically produce realistic corrections. Instead, they appear to prepare the ground for other components of the treatment programme, such as behavioral experiments. They can further be used to help the client/patient realize that when they are anxious or afraid, they have probably overestimated the likelihood of harm.

A common problem encountered in attempting to modify over-estimations of the probability of a feared event is that the patient neglects information that is counter to the feeling that a dreaded event is likely to occur. In order to restore a realistic balance it can be helpful for the patient to have easy access to positive evidence that is being ignored. For example, a competent lawyer was plagued by fears that her colleagues would be very critical of any error 
that she made and consequently checked her work, such as preparing contracts, over and over again. On examination it emerged that she had an excellent record, had made no significant errors, and been promoted regularly. She was overly responsible and when the senior partner in the firm gave her increasingly important work to do, she responded to it as if it were an implied criticism. In fact, it was a vote of confidence in her work. She was encouraged to prepare a small card setting out the positive facts about her performance and to refer to it whenever she found herself checking or engaging in self-doubt. It contained these items: I have been promoted regularly; I have never made a significant error; I am being given increasingly responsible work; each year I have received a handsome bonus.

The effects of repeated checking on a patient's estimates of the probability of the anticipated misfortune (usually minimal) can be measured in behavioral experiments. They show that most repetitive checking does little or nothing to reduce the probability estimate of the feared event.

Over-estimations of the seriousness of the feared event.

The modification of over-estimating the seriousness of the anticipated events, to catastrophize about the feared consequence, is dealt with in a manner similar to treating the overestimations of probability. (Feelings of responsibility tend to produce inflated estimates of the seriousness of the anticipated misfortune (e.g., Menzies, Harris, Cummings, \& Einsten, 2000; Arntz et al., 2007; Haring, 2005). A rough calculation is made of the number of times in which the seriousness of a feared outcome was excessive, and the number of expected catastrophes. This figure is balanced against the actual number of serious outcomes. On close examination many of the dreaded catastrophes turn out to be relatively trivial (e.g., 'I forgot to fold the laundry'). The cognitive biases that operate in probability estimates also come into play in 
estimating the seriousness of the feared event. For example, 'if I am responsible then the consequences will be catastrophic'. By contrast if someone else is responsible, the consequences will be minor. Thought-action-fusion also operates: 'If my thoughts about an accident/mishap increase the probability of such an event occurring, the consequences are likely to be extremely serious--it will be a horrific accident.'

As with the estimates of the probability of a feared event, so too can the estimates of the seriousness of the feared event be measured in behavioral experiments. Do repetitions of checking reduce the estimated seriousness of the feared event? Rarely. Added together the behavioral experiments enable the patient to collect credible personal evidence of the inefficacy of their repeated checking behavior.

\section{Responsibility.}

In most cases, excessive responsibility is a central element of the compulsive checking, and the roots of the responsibility are analyzed and explored, with emphasis on the personal significance that the patient attaches to these feelings. What is the range of the responsibility? Which situations/tasks evoke high levels of responsibility? How did it develop? Are you ever free of it? Is there anyone with whom you can willingly share the responsibility? Are you attempting to protect other people, and if so, whom and why? Are you primarily trying to protect yourself? If yes, are they specially concerned about health matters, even a specific illness (cancer, mental illness) and/or the possibility of losing control? (See semi-structured interview in Appendix A).

Once a degree of clarity about this significance is achieved, cognitive modification is undertaken and then followed by a number of in-session exercises that are matched to the patient's particular needs. This work is a development of previous attempts to modify 
responsibility (e.g., Ladouceur et al., 1996; Lopatka \& Rachman, 1995; Radomsky, Rachman \& Hammond, 2001).

Cognitive modification covers a lot of ground, depending on the needs of the particular case. Aspects that are commonly discussed include the origin of the feelings of responsibility, the source of the responsibility, who introduced and allocated the responsibility, who was the patient originally responsible to, currently responsible to? Is the responsibility shared, is it fairly shared, and who decides? What happens if the patient resists excessive responsibility? What has happened in the past? Did anyone criticize you severely? If yes, details. Does criticism nowadays upset you? Are you fearful of possible criticism? Are you hard on yourself? Do you engage in self-criticism? What is the connection between the feelings of responsibility and the compulsive checking? What are the connections between the responsibility and feelings of self-criticism, and the responsibility and guilt? Has any significant misfortune event occurred because you neglected your responsibility, or were careless? Assessing the relationship between responsibility and control is also important as they are closely connected for many individuals (Moulding, Kyrios, Doron, \& Nedeljkovic, 2009).

\section{$\underline{\text { Pie charts. }}$}

The exercises include the use of a pie chart to analyze the allocation of responsibility between the patient and other people (Salkovskis, 1999; Van Oppen \& Arntz, 1994). A pie chart is useful for analyzing, and ultimately modifying the patients' appraisals of their responsibility for preventing mishaps, catastrophes, misfortunes. Their 'allocation of responsibility' is assessed by collecting information about the person/s whom they believe bear some responsibility for preventing specific mishaps (e.g., ensuring that the home is properly secured before leaving). The patient then rates the percentage of each person's responsibility; for example, father has 
$50 \%$, mother has $55 \%$, sister has $40 \%$. These slices of responsibility are then entered in a pie chart. Finally, ask the patient to rate and enter their own responsibility. Typically their own responsibility is highly inflated, and when all of the slices of responsibility are summated they exceed $100 \%$, sometimes extravagantly so, and cannot be contained in the pie-chart. There evidently is an over-estimation of responsibility.

After explaining the purpose of constructing the pie chart it is well to give the patient a few examples of how to assess responsibility For example, "If you are driving a car in bad weather, and you have two passengers, one in the front seat and one in the back, how responsible would you feel for ensuring a safe journey?" "How responsible would the passenger in the front seat be?" "How responsible would the passenger in the back seat be?" "If you are the first person to leave home in the morning, and at least two relatives/friends are still in the house, how responsibility would you feel for ensuring the safety of the home?" "How responsible would they be for ensuring the safety of the home?" "If you are the last person to leave the home in the morning, how responsible would you feel for ensuring the safety of the house?"

After this preliminary work pie charts are used for analyzing the patient's perceived responsibility for the specific tasks/situations that regularly instigate their compulsive checking. Therapeutic progress can be assessed by repeating the pie chart exercises at selected intervals. As the treatment program is self-correcting, persistently unrealistic estimates of one's responsibility are an indication that supplementary or alternative therapeutic tactics are necessary (see below).

The major problem encountered in attempting to modify the patient's inflated and unrealistic feelings of responsibility is the adhesiveness of their feelings. They are perfectly capable of perceiving the irrationality of their exaggerated feelings of responsibility but shrinking them, or sharing them, or transferring them or even suspending them briefly, can be 
extremely difficult. Changes in responsibility are vigorously resisted. They find it upsetting and even unacceptable. In an experimental analysis of compulsive checking that was carried out in patients' home the patients were cooperative but many found it exceedingly difficult to suspend or transfer responsibility for certain household tasks such as using the stove, even for a few minutes, and even though the experimenters were present and accepted responsibility for all outcomes (Lopatka \& Rachman, 1995). It became necessary to prepare written contracts with them that covered the short period of the experiment. Suspending or transferring responsibility is not emotion-free. The process of using contracts is shown in VIDEO 2a and VIDEO $2 \mathrm{~b}$.

\section{(Please view Video 2 a followed by Video $2 b$ here.)}

Despite the potential difficulties, progress can be made, but it is slow work at first.

Fortunately, the patients experience considerable relief and release as they succeed in circumscribing their feelings of inflated responsibility, and the compulsive checking is reduced. Behavioral experiments can be effective, disclosures and discussions with affected people are helpful, and a re-drawing of the lines of responsibility between the patient and friends/relatives can be effective. In the behavioral experiments, temporary transfers of responsibility and temporary suspensions of responsibility can be helpfully informative. The pie chart technique is used in and out of therapy sessions, as appropriate.

\section{Practising the transfer of responsibility.}

Responsibility is transferred firstly to the therapist and then to friends and relatives. This part of the treatment includes behavioral experiments in order to collect information and hone the tactic. Results from these experiments are gathered and collaboratively interpreted. Normally, early transfers are difficult, but as they become easier, anxiety tends to decrease along with checking behaviour. 


\section{Practising the delay tactic.}

Practising the delay tactic is achieved by agreeing with oneself to postpone the checking for one or more hours/days (generally, the urges decline and by the time the agreed checking time arrives, patients often find that the need to check has decreased or even disappeared). As the patient makes progress in session, the exercises are carried out in the general environment of the clinic. When the patients are observed to use the responsibility exercises effectively, they are encouraged to extend the methods to their home and/or work situations. They are also advised to gather information about what constitutes normal checking behavior, as illustrated in VIDEO 3a and VIDEO $3 b$.

(Please view Video 3a followed by Video 3b here.)

Dealing with the client's/patient's resistance to modifying inflated responsibility.

A major problem encountered in therapy is the patient's resistance to modifying their feelings of responsibility. It can evoke such strong feelings of tension, anxiety, guilt, distress that the patient is unable/unwilling to suspend their responsibility even for a minute, or to risk even a brief transfer of responsibility to the therapist or other people. In these cases, it is necessary to exercise patience and start with the easiest and most acceptable early steps. Progress can be made by couching the attempt as a behavioral experiment:

In the distance tactic the patient is asked to rate the degree of responsibility they would have for ensuring the safety of a significant person who lives (1) close by or even in the same home as against the responsibility they would feel (2) if the same person were in a distant country and out of contact for more than a month. (Feelings of protective responsibility for other people often have a physical boundary; if the person is very far away responsibility becomes 'impossible'. Interestingly, the full feelings of responsibility return as soon as the person being 
protected comes back into close geographical contact.) The distancing tactic can be helpful in its own right and also provide the basis for the suspension and/or transfer of responsibility.

\section{Countering the sustaining factors.}

The next part of the treatment is directed at the self-perpetuating cycle. It is explained that 'checking causes more checking' and feeds one's self-doubt and anxiety about a perceived failing memory and dysfunctional concentration. Not surprisingly, patients who repeatedly check their doors before leaving home, even returning several times to re-check them, become frustrated and annoyed at themselves. At one level they know that they have checked the doors satisfactorily, but they are nevertheless driven to check again and again. The repeated checking produces self-doubt and leads one to question the reliability of one's memory. Matters are compounded because they are also aware that in other circumstances, such as work, their memory is normal. Accumulating experimental evidence (van den Hout \& Kindt, 2003a; 2003b; Radomsky et al., 2006; Coles et al., 2006) shows that in these cases the problem is not a neurological deficit but rather a loss of confidence in one's memory. Paradoxically, this loss of confidence is generated by the repeated checking. It is a secondary effect of compulsive checking.

This explanation is given and then supplemented by behavioral experiments in which the patient's memory and attention are assessed after a single check and after a large amount of checking behavior (it is helpful to suggest comparing the effects of a single check to the effects of 10 minutes of checking rather than comparing the effects of a single check against the effects of 25 checks, for example, because counting the checks can temporarily increase their salience). After a few experiments of this sort are completed in the clinic, the patient is encouraged to carry out similar experiments at home/work. Inevitably they find that the more they check, the less 
sure they are. This is demonstrated in VIDEO $4 \mathrm{a}$ and VIDEO $4 \mathrm{~b}$. The consequences of this new information about doubt and uncertainty are discussed in terms of the intent of the checking behavior, and conclusions normally stipulate that the best way to be sure is not to check.

$$
\text { (Please view Video 4a followed by Video } 4 \mathrm{~b} \text { here.) }
$$

\section{Response Prevention.}

There is fresh debate about the purpose of response prevention (RP) in CBT for OCD. The safest conclusion is that it reduces symptoms through a combination of behavioral and cognitive mechanisms. The nature and purpose of the RP tactic is explained to the client/patient, and in many instances can be demonstrated in the clinic. The patient is encouraged to use RP, and to use it early. As soon as the checking urges occur, the patient should 'switch on' the RP tactic - prevent the checking behavior. It is important to ascertain whether or not the patient also engages in 'mental', covert checking, and the RP tactic is applied to these urges as well. In the

early stages of treatment it can be useful to combine the RP tactic with that of deliberate delay; many urges show a degree of spontaneous decay and when the 'agreed' delay period ends, it is commonly found that the urge is so weak that RP is easy.

\section{Dealing with requests for reassurance.}

The development of self-doubting, fed by a loss of confidence in one's memory and other problems such as a loss of confidence in one's judgment, generates strong urges for reassurance from other people. The urges can be remarkably powerful and difficult to inhibit even though the reassurance produces at best only transient relief, and in full recognition that other people quickly tire of repeating the same reassuring phrases time after time. The repeated requests for reassurance are often unrecognized attempts to recruit another person to carry out some of the 
checking - in addition to attempting to spread the responsibility to others (Rachman, 2002;

Parrish \& Radomsky, 2009).

A confusing aspect of reassurance-seeking is that it appears to be a request for information but in nearly every instance the patient knows the answer in advance; they have the information. In most cases they have heard the information repeatedly. The requests are attempts to reduce the anxiety, and this they succeed in accomplishing but only briefly and minimally. The requests can also be indirect attempts to devolve one's sense of responsibility - make other people share some of the responsibility.

In almost all circumstances the provision of the requested reassurance strengthens the compulsive urges, and in therapy both the requests and the repeated surrender to the requests, are discouraged. There are a few exceptions in which the timely provision of useful information can be genuinely reassuring, but repetitions are best avoided. It is likely that the above tactics on reducing responsibility and perceptions of harm, combined with work on the self-perpetuating nature of checking behavior will be quite useful if/when the focus of the treatment is applied to reassurance seeking. In some cases, collaboration with family members and/or other loved ones (with the consent of the client/patient) can also be quite helpful in reducing the provision of reassurance; however, achieving a reduction in requests for reassurance is the primary target of this work.

\section{Modifying Cognitive Biases.}

The distinction between thinking about a catastrophe and the occurrence of a catastrophe is used to illustrate the first of two common forms of cognitive bias, namely that in certain circumstances we have a tendency to over-estimate the probability of misfortunes/accidents. In cases of compulsive checking there is a tendency to over-estimate the probability of a misfortune 
if the patient is in a position of responsibility: 'it will happen because I am in charge'. In contrast, the same patient will provide a more realistic probability of an accident/misfortune occurring if they feel that they have no responsibility in the circumstances. In the example of the pharmacist above, he rated the probability that he would make a significant prescription error as many times greater than the probability that a colleague would make such an error.

The cognitive bias, thought-action-fusion (TAF), involves confusion between one's thoughts and external events (Rachman, 1993; Rachman, Thordarson, Shafran, \& Woody, 1995; Shafran \& Rachman, 2004). In particular, there is a tendency to feel and believe that thinking about a misfortune (say, an accident befalling a relative) actually increases the probability that the misfortune will occur. The occurrence of thought-action biases raises the person's anxiety, and guilt, and the common reaction is to neutralize the thought. This can take the form of compulsively checking for safety, of seeking reassurance, and/or of covertly checking. A second form of TAF, the morality bias, is the belief that having an unacceptable thought about someone else (e.g., harming them) is equivalent to actually harming them. Preventive and/or checking behavior often follows. Both forms cause guilt.

The phenomenon of TAF is explained, with clinical examples, and patients are encouraged to identify and then dismiss the connection, the fusion. Specific examples provided by the patient are collected and disconfirmed in therapy. The patient's answers to the questions on the TAF Scale (Shafran et al., 1996) provide a useful guide during therapy; if they are prone to overestimate the probability of particular misfortunes special attention is paid to unraveling the examples endorsed or offered by the patient. The TAF Scale is also used a self-correcting measure of progress. In this way the Scale is used as an instrument in therapy as well as an assessment measure. By the end of therapy, the scores should be within the normal range. 
Another relevant, albeit less common, cognitive error that arises from inflated responsibility is the sense that one is responsible for misfortunes over which one has no control whatsoever, even events that occur miles away or even continents away. As with all cognitive biases or errors, personal examples are collected and disconfirmed. Behavioral experiments are often quite helpful here, including the exercise to ascertain whether or not the client/patient can cause small misfortunes or distant catastrophes with their thoughts or actions.

Dealing with feelings of guilt.

Excessive and/or inappropriate guilt occurs in a range of disorders and therapeutic methods are used as necessary, but in cases of compulsive checking the focus is placed on the close connection between responsibility and guilt (Rachman, 1993). During the process of reducing the excessive feelings of responsibility, the connection with guilt is elaborated, and examples provided by the patient are used to illustrate the link between the two. As responsibility is reduced, the guilt declines.

Reducing hyper-vigilance.

Patients who believe that they have special, pivotal responsibility for preventing harm coming to others and/or themselves often feel compelled to keep watch, to be hyper-vigilant to possible threats. They see threats in situations that appear unremarkable to everyone else. An extreme example of such hyper-vigilance afflicted a patient who was a professional engineer. He felt that he had a special responsibility for protecting people from being harmed by discarded detonators, and whenever he was in a public space constantly scanned for threatening material. As a result he was compelled to closely examine any objects that were metallic or might be metallic, and would repeatedly return to any place in which he had encountered a potential detonator. Once there he would engage in detailed repeated scanning of the area. As soon as he 
entered a public space, especially parks or other places where children congregated, he was on duty, scanning intensively.

In this case, as in others, the roots of his need to be a public protector and constantly on duty, were analyzed. His elevated responsibility was the product of both a childhood in a dysfunctional family and his professional training. The analysis was followed by a description of the nature of selective attention: we are all capable of a degree of deliberate selection in choosing to attend or not to attend to specific stimuli; at other times attention wanders without direction or a deliberate aim. During periods of threat, attention becomes highly focused on the source of the perceived threat. If the threat is unclear, ambiguous or changing, one scans repeatedly.

In order to reduce the patient's inflated and persistent need to be hyper-vigilant, they are taught how to allow themselves periods off duty from responsibility. The analogy of air-traffic controllers is helpful here. When on duty, the controllers have to be fully focused and vigilant at all times. As this can be very tiring, it is common practice for the controllers to work for 2 hours, then take break for 1 hour, and so on. They switch from maximum on duty vigilance to minimal off duty vigilance throughout the day. During their off duty periods they can still hear the aircraft landing and departing but they need not and do not attend to them. On returning to an on duty status, they are once again fully attentive and vigilant. A description of the on duty versus off duty tactic is given to clients/patients, followed by a set of simple exercises in which the patient is trained to switch at will from being on duty to off duty, and from off duty to on duty. "When air-traffic controllers are on duty they have to pay full attention to their screens, to concentrate on their essential scanning and actions. Because of the tiring effort involved, they generally work for two hours and then have a one hour off duty break, followed by a second two hour period on duty, etc. During the off duty period they relax elsewhere at the airport. Even though they can 
still hear the aircraft overhead, the landings and take-offs, they pay no attention. They are off duty. Instead they chat or read or write poetry. When they return to on duty their attention is again fully engaged. When you practice your on duty and off duty exercises, think about how you can also become competent in switching your attention on and off."

Initially the on and off duty exercises are practiced during sessions, and as soon as the patients perceive the contrast and learn how to switch from one to the other, they are asked to practice for up to 10 minutes at a time in the clinic environment. "Put yourself off duty for 10 minutes and then walk around the hospital." The contrast is: "Put yourself on duty - keep an eye open for any potential problems or threats to safety. Remain on duty throughout your 10 minute walk around the hospital." Once the patients report success in the hospital area, they are encouraged to practice the exercises in the home environment, progressing steadily from being off duty for an hour or two to entire days off duty. Their progress in using the on/off duty is monitored as sessions progress. These exercises can be extremely effective. When they acquire the skill of switching to on duty or off duty as appropriate, the person's level of general tension declines, and the successful use of the tactic also chips away at their feelings of inflated responsibility. They are reminded that in the off duty state there is no need for them to scan for potential risks, or remember them, or take action, or intervene.

\section{Concluding comments}

The treatment of compulsive checking has been enhanced by the provision of a cognitive framework for understanding the problem and for subsequent intervention. The use of behavioral experiments to illustrate that it is the repeated checking that is causing memory distrust is a potent intervention and, together with the range of other methods described, we are well placed to improve outcomes for people with this debilitating problem. 


\section{References}

Abramowitz, J. S. (2006). The psychological treatment of Obsessive-Compulsive Disorder. The Canadian Journal of Psychiatry, 51, 407-416.

Arntz, A., Voncken, M., \& Goosen, A. C. A. (2007). Responsibility and Obsessive-Compulsive Disorder: An experimental test. Behaviour Research and Therapy, 45, 425-435.

Beck, A. T., Steer, R. A., \& Garbin, M. G. (1996). Beck depression inventory manual (2 ${ }^{\text {nd }}$ ed.). San Antonio: Psychological Corporation.

Clark, D. A. (2004). Cognitive-behavioral therapy for OCD. New York (NY): Guilford Press.

Clark, D. M., \& Fairburn, C. G. (Eds.) (1997). Science and practice of cognitive behaviour therapy. New York: Oxford University Press.

Coles, M. E., Radomsky, A. S., \& Horng, B. (2006). Exploring the boundaries of memory distrust from repeated checking: Increasing external validity and examining thresholds. Behaviour Research and Therapy, 44, 995-1006.

Coles, M. E. \& Schofield, C. A. (2008). Assessing the development of inflated responsibility beliefs: The pathways to inflated responsibility beliefs scale. Behaviour Therapy, 39, $322-335$.

Cottraux, J., Bouvard, M. A., \& Milliery, M. (2005). Combining pharmacotherapy with cognitive-behavioral interventions for Obsessive-Compulsive Disorder. Cognitive Behaviour Therapy, 34, 185-192.

Eddy, K. T., Dutra, L., Bradley, R., \& Westen, D. (2004). A multidimensional meta-analysis of psychotherapy and pharmacotherapy for Obsessive-Compulsive Disorder. Clinical Psychology Review, 24, 1011-1030. 
Fisher, P. L., \& Wells, A. (2005). How effective are cognitive and behavioral treatments for Obsessive-Compulsive Disorder? A clinical significance analysis. Behaviour Research and Therapy, 43, 1543-1558.

Foa, E. B., Liebowitz, M. R., Kozak, M. J., Davies, S., Campeas, R., Franklin, M. E., et al. (2005). Randomized, placebo-controlled trial of exposure and ritual prevention, clomipramine, and their combination in the treatment of Obsessive-Compulsive disorder. The American Journal of Psychiatry, 162, 151-161.

Freeston, M. H., Ladouceur, R., Gagnon, F., Thibodeau, N,. Rhéaume, J., Letarte, H., \& Bujold, A. (1997). Cognitive-behavioural treatment of obsessive thoughts: a controlled study. Journal of Consulting and Clinical Psychology, 65, 405-413.

Goodman, W. K., Price, L. H., Rasmussen, S. A., Mazure, C., Fleischmann, R. L., Hill, C. L., et al. (1989). The Yale-Brown Obsessive Compulsive Scale. I. Development, use, and reliability. Archives of General Psychiatry, 46, 1006-1011.

Haring, M. L. (2005). To check or not to check: A test of a cognitive theory of compulsive checking. Dissertation Abstracts International: Section B: The Sciences and Engineering, $66,6922$.

Jenike, M. A., Baer, L., \& Minichiello, W. E. (Eds.) (1998). Obsessive-Compulsive disorders: Practical management (3rd ed.). Chicago: Mosby.

Ladouceur, R., Léger, E., Rhéaume, J., \& Dubé, D. (1996). Correction of inflated responsibility in the treatment of Obsessive-Compulsive disorder. Behaviour Research and Therapy, 34, 767-774. 
Ladouceur, R., Rheaume, J., \& Aublet, F. (1997). Excessive responsibility in obsessional concerns: A fine-grained experimental analysis. Behaviour Research and Therapy, 35, 423-427.

Ladouceur, R., Rheaume, J., Freeston, M. H., Aublet, F., Jean, K., Lachance, S., et al. (1995). Experimental manipulations of responsibility: An analogue test for models of ObsessiveCompulsive Disorder. Behaviour Research and Therapy, 33, 937-946.

Lopatka, C. \& Rachman, S. (1995) Perceived responsibility and compulsive checking: An experimental analysis. Behaviour Research and Therapy, 33, 673-684.

Menzies, R. G., Harris, L. M., Cumming, S. R., Einsten, D. A. (2000). The relationship between inflated personal responsibility and exaggerated danger expectancies in obsessivecompulsive concerns. Behaviour Research and Therapy, 38, 1029-1037.

Moulding, R., Kyrios, M., Doron, G., \& Nedeljkovic, M. (2009). Mediated and direct effects of general control beliefs on obsessive compulsive symptoms. Canadian Journal of Behavioural Science/Revue canadienne des sciences du comportement, 41, 84-92.

Rachman, S. (1993). Obsessions, responsibility and guilt. Behaviour Research and Therapy, 31, $149-154$.

Rachman, S. (2002). A cognitive theory of compulsive checking. Behaviour Research and Therapy, 40, 625-639.

Rachman, S. (2003). The treatment of obsessions. New York (NY): Oxford University Press.

Rachman, S., Thordarson, D. S., Shafran, R., \& Woody, S. R. (1995). Perceived responsibility: Structure and significance. Behaviour Research and Therapy, 33, 779-784.

Radomsky, A. S., Gilchrist, P. T., \& Dussault, D. D. (2006). Repeated checking really does cause memory distrust. Behaviour Research and Therapy, 44, 305-316. 
Radomsky, A. S., Rachman, S. J., \& Hammond, D. (2001). Memory bias, confidence and responsibility in compulsive checking. Behaviour Research \& Therapy, 39, 813-822.

Salkovskis, P. M. (1985). Obsessional-compulsive problems: A cognitive-behavioural analysis. Behaviour Research \& Therapy, 23, 571-583.

Salkovskis, P. M. (1999). Understanding and treating Obsessive-Compulsive Disorder. Behaviour Research and Therapy, 37, S29-S52.

Salkovskis, P. M., Shafran, R., Rachman, S. J., \& Freeston, M. H. (1999). Multiple pathways to inflated responsibility beliefs in obsessional problems: Possible origins and implications for therapy and research. Behaviour Research and Therapy, 37, 1055-1072.

Shafran, R. (1997). The manipulation of responsibility in Obsessive-Compulsive Disorder. British Journal of Clinical Psychology, 36, 397-407.

Shafran, R., \& Rachman, S. (2004) Thought-action fusion: A review. Journal of Behavior Therapy and Experimental Psychiatry, 35, 87-107.

Shafran, R., Thordarson, D. S., \& Rachman, S. (1996). Thought-action fusion in Obsessive Compulsive Disorder. Journal of Anxiety Disorders, 10, 379-391.

Sookman, D. \& Steketee, G. (2007). Directions in Specialized Cognitive Behavior Therapy for Resistant Obsessive-Compulsive Disorder: Theory and Practice of Two Approaches. Cognitive and Behavioral Practice, 14, 1-17.

Stanley, M. A. \& Turner, S. M. (1995). Current status of pharmacological and behavioral treatment of )bsessive-Compulsive Disorder. Behavior Therapy, 26, 163-186. 
van den Hout, M. A., Engelhard, I. M., de Boer, C., du Bois, A., \& Dek, E. (2008). Perseverative and compulsive-like staring causes uncertainty about perception. Behaviour Research and Therapy, 41, 1300-1304.

van den Hout, M. A., Engelhard, I. M., Smeets, M., Dek, E. C. P., Turksman, K., \& Saric, R. (2009). Uncertainty about perception and dissociation after compulsive-like staring: Time course of effects. Behaviour Research and Therapy, 47, 535-539.

van den Hout, M. A., \& Kindt, M. (2003a). Repeated checking causes memory distrust. Behaviour Research and Therapy, 41, 301-316.

van den Hout, M. A., \& Kindt, M. (2003b). Phenomenological validity of an OCD-memory model and the remember/know distinction. Behaviour Research and Therapy, 41, 369378.

van den Hout, M. A., \& Kindt, M. (2004). Obsessive-Compulsive Disorder and the paradoxical effects of perserverative behaviour on experienced uncertainty. Journal of Behaviour Therapy and Experimental Psychiatry, 35, 165-181.

Van Oppen, P., \& Arntz, A. (1994). Cognitive therapy for Obsessive Compulsive Disorder. Behaviour Research and Therapy, 32, 79-87.

Whittal, M. L., Robichaud, M., Thordarson, D. S., \& McLean, P. D. (2008). Group and individual treatment of Obsessive-Compulsive Disorder using cognitive therapy and exposure plus response prevention: A 2-year follow-up of two randomized trials. Journal of Consulting and Clinical Psychology, 76, 1003-1014.

Whittal, M. L., Thordarson, D. S., \& McLean, P. D. (2005). Treatment of Obsessive-Compulsive Disorder: Cognitive behavioural therapy vs. exposure and response prevention. Behaviour Research and Therapy, 43, 1559-1574. 
Wilhelm, S. (2001). Obsessive-Compulsive Disorder. In William J. Lyddon \& John V. Jones Jr. (Eds.), Empirically Supported Cognitive Therapies: Current and Future Applications (pp. 118-133). New York, NY: Springer Publishing Co. 


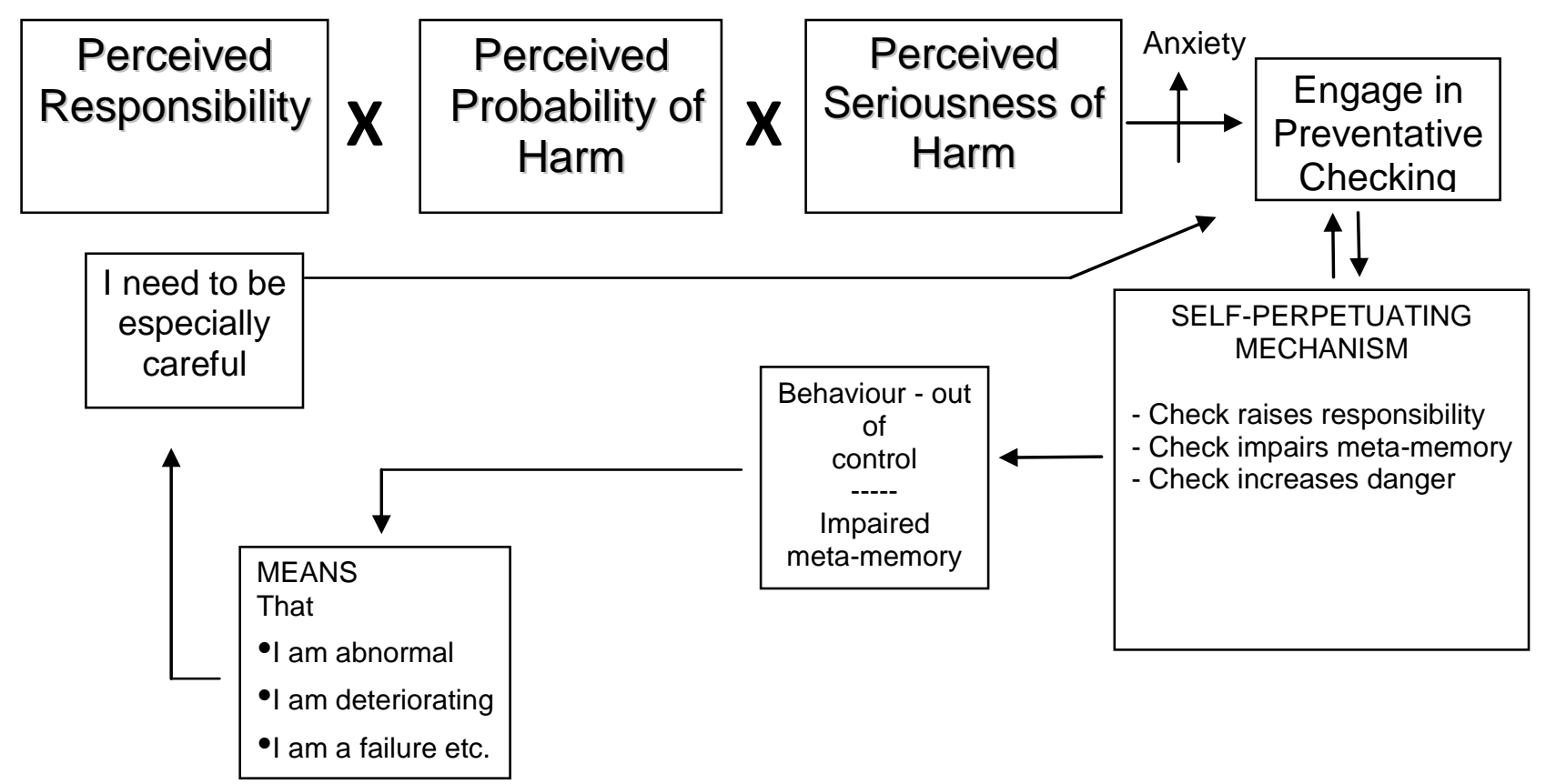

Figure 1: Elements which cause the development and maintenance of compulsive checking behavior (Composite figure adapted from Rachman, 2002). Reprinted with permission. 
Appendix A: Semi-structured interview for compulsive checking

1. Describe the type of repeated checking that you carry out (If the patient has more than one distinctive intense and serious checking behavior, some of the listed questions will need to be asked for each of the types of checking.)

2. Is there anything in particular that sets it off?

3. Why do you feel the urge to check repeatedly?

4. What is the purpose of your checking?

5. Do you try to resist the urge to check?

6. What would happen if you successfully resist the urge to check?

7. What would happen if you decided that you will no longer yield to the urges to check?

8. Where do you carry out this checking?

9. When do you do this checking?

10. How long does it last?

11. Can you stop it whenever you choose to do so?

12. What happens if someone interrupts your checking?

13. If you fail to check, or do it unsatisfactorily, does it bother you?

14. Do you regard yourself as a responsibility person?

15. If yes, would you say that you are much more responsibility than other people, much less responsibility than other people, or about average?

16. Do people who know you regard you as a responsibility person?

17. Do you ever feel that you are burdened by too much responsibility?

18. If yes, when did it begin and how has it developed? 
19. As a child, were you given a great deal of responsibility, or very little responsibility or an average amount?

20. Was there ever an event that had a major impact on your feelings of responsibility?

21. Do you welcome new or added responsibility?

22. Do you avoid or resist new or added responsibility?

23. Is it easy for you to share responsibility?

24. Is it easy for you to hand over responsibility to someone else?

25. Do you feel that you have a special responsibility for protecting other people from harm? If yes, details.

26. Was there ever an event that had a major impact on your need to check repeatedly?

27. Are you ever troubled by distressing feelings of guilt?

28. Do you frequently feel guilty?

29. Do you put a lot of thought and effort into checking your own health?

30. Do you ever check to make sure that you have not and will not lose control of yourself?

31. Do you have a strong need to seek reassurance from other people?

32. Do ever feel that your memory is failing?

33. Do you think that you need to check repeatedly because your memory is unreliable?

34. Do you think that you need to check repeatedly because your mind gets "fuzzy"?

35. Are you especially sensitive to criticism?

36. Are you critical of yourself? Do you often blame yourself?

37. Have you ever been severely criticized? If yes, details.

38. Is it easier for you to leave home in the morning if someone else is still in the house? If yes, how do you explain this? 
39. Are you less anxious about harming a pedestrian if someone else is driving the car? If so, why is this?

40. What would be the worst thing that could happen if you failed to check satisfactorily?

41. Do you ever get an image, a picture in your mind, of what would happen if you failed to check satisfactorily?

42. Are you slow at completing tasks?

43. When you are carrying out a repetitive task, does it ever feel as if your brain has switched off?

44. Do you often ask other people for reassurance?

45. Do you have any difficulties driving a car?

46. Would you describe yourself as a perfectionist?

47. Are you ever troubled by unwanted, uninvited, unacceptable thoughts/images/impulses?

48. Have you or anyone in your family ever experienced a serious misfortune? 
Appendix B: Personal Significance Scale for compulsive checking (PSS-CHK)

\section{P. S. Scale (FORM PSS)}

Please read the following statements carefully and circle the number that best corresponds to the extent to which you agree with each statement regarding your checking behaviour.

Specific checking behaviour:

Please use the following scale:

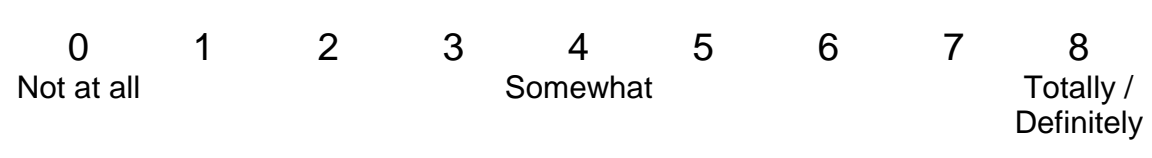

1. Is it important for you to conceal from other people the extent of your $\quad \begin{array}{lllllllll}0 & 1 & 2 & 3 & 4 & 5 & 6 & 7 & 8\end{array}$ checking?

2. Do you feel that something bad will happen if you personally fail to $\quad \begin{array}{lllllllll}0 & 1 & 2 & 3 & 4 & 5 & 6 & 7 & 8\end{array}$ carry out your checking?

3. Do you think that people would regard you as really weird if they saw $\quad \begin{array}{lllllllll}0 & 1 & 2 & 3 & 4 & 5 & 6 & 7 & 8\end{array}$ you checking repeatedly?

4. Do you think that people would regard you as a weak person if they $\quad \begin{array}{lllllllll}0 & 1 & 2 & 3 & 4 & 5 & 6 & 7 & 8\end{array}$ saw you checking repeatedly?

5. Do you think that people would regard you as weird if they heard

$\begin{array}{lllllllll}0 & 1 & 2 & 3 & 4 & 5 & 6 & 7 & 8\end{array}$ about your repeated checking?

6. Do you think that people would criticize or condemn you if they saw $\quad \begin{array}{lllllllll}0 & 1 & 2 & 3 & 4 & 5 & 6 & 7 & 8\end{array}$ you checking repeatedly?

7. Does your repeated checking mean that there is something seriously $\quad \begin{array}{lllllllllll}0 & 1 & 2 & 3 & 4 & 5 & 6 & 7 & 8\end{array}$ wrong with you?

8. Does your repeated checking mean that you are a really weak person? $\quad \begin{array}{llllllllllllllllllllll} & 0 & 1 & 3 & 4 & 5 & 7 & 8\end{array}$ 
9. Does your repeated checking mean that you are a hopeless person?

10. Does your repeated checking mean that one day you might go crazy?

11. Do you feel that unless you personally check for safety, someone will be harmed?

12. Do you feel that you have a special responsibility for keeping other people safe?

13. Do you think that your memory is failing you?

14. Are you the sort of person who is constantly watching out for signs of danger?

15. Are you the sort of person who sees danger when other people do not see it?

16. Are you the sort of person who has to be very very sure that the house is safe?

17. Are you the sort of person who worries far too much about the safety of other people?

18. Do you have a special responsibility for protecting other people?

19. Do you criticize yourself for being careless?

20. Have you lost confidence in your memory?

21. Have you lost confidence in your judgement?

22. Are you especially sensitive to criticism?

23. Should you fight against and resist the urges to check repeatedly? $\begin{array}{lllllllll}0 & 1 & 2 & 3 & 4 & 5 & 6 & 7 & 8\end{array}$

$\begin{array}{lllllllll}0 & 1 & 2 & 3 & 4 & 5 & 6 & 7 & 8\end{array}$

$\begin{array}{lllllllll}0 & 1 & 2 & 3 & 4 & 5 & 6 & 7 & 8\end{array}$

$\begin{array}{lllllllll}0 & 1 & 2 & 3 & 4 & 5 & 6 & 7 & 8\end{array}$

$\begin{array}{lllllllll}0 & 1 & 2 & 3 & 4 & 5 & 6 & 7 & 8\end{array}$

$\begin{array}{lllllllll}0 & 1 & 2 & 3 & 4 & 5 & 6 & 7 & 8\end{array}$

$\begin{array}{lllllllll}0 & 1 & 2 & 3 & 4 & 5 & 6 & 7 & 8\end{array}$

$\begin{array}{lllllllll}0 & 1 & 2 & 3 & 4 & 5 & 6 & 7 & 8\end{array}$

$\begin{array}{lllllllll}0 & 1 & 2 & 3 & 4 & 5 & 6 & 7 & 8\end{array}$

$\begin{array}{lllllllll}0 & 1 & 2 & 3 & 4 & 5 & 6 & 7 & 8\end{array}$

$\begin{array}{lllllllll}0 & 1 & 2 & 3 & 4 & 5 & 6 & 7 & 8\end{array}$

$\begin{array}{lllllllll}0 & 1 & 2 & 3 & 4 & 5 & 6 & 7 & 8\end{array}$

$\begin{array}{lllllllll}0 & 1 & 2 & 3 & 4 & 5 & 6 & 7 & 8\end{array}$

$\begin{array}{lllllllll}0 & 1 & 2 & 3 & 4 & 5 & 6 & 7 & 8\end{array}$

$\begin{array}{lllllllll}0 & 1 & 2 & 3 & 4 & 5 & 6 & 7 & 8\end{array}$ 